\title{
Effects of beta-alanine supplementation and interval training on physiological determinants of severe exercise performance
}

\author{
Micah Gross • Chris Boesch • Christine S. Bolliger • \\ Barbara Norman · Thomas Gustafsson • \\ Hans Hoppeler • Michael Vogt
}

Received: 9 May 2013 / Accepted: 28 October 2013 / Published online: 9 November 2013

(C) Springer-Verlag Berlin Heidelberg 2013

\begin{abstract}
Introduction We aimed to manipulate physiological determinants of severe exercise performance. We hypothesized that (1) beta-alanine supplementation would increase intramuscular carnosine and buffering capacity and dampen acidosis during severe cycling, (2) that high-intensity interval training (HIT) would enhance aerobic energy contribution during severe cycling, and (3) that HIT preceded by betaalanine supplementation would have greater benefits.

Methods Sixteen active men performed incremental cycling tests and $90-\mathrm{s}$ severe (110\% peak power) cycling tests at three time points: before and after oral
\end{abstract}

Communicated by Klaas R. Westerterp/Håkan Westerblad.

M. Gross $(\varangle) \cdot$ H. Hoppeler $\cdot$ M. Vogt

Institute for Anatomy, University of Bern, Baltzerstrasse 2, 3012 Bern, Switzerland

e-mail: micah.gross@baspo.admin.ch

M. Gross · C. S. Bolliger

Graduate School for Cellular and Biomedical Sciences,

University of Bern, Bern, Switzerland

M. Gross $\cdot$ M. Vogt

Swiss Federal Institute of Sport, Magglingen, Switzerland

C. Boesch · C. S. Bolliger

Department of Clinical Research, University of Bern, Bern,

Switzerland

C. Boesch · C. S. Bolliger

Department of Diagnostic, Interventional, and Pediatric

Radiology, University of Bern, Bern, Switzerland

B. Norman · T. Gustafsson

Division of Clinical Physiology, Department of Laboratory

Medicine, Karolinska Institutet, Karolinska University Hospital,

Huddinge, Stockholm, Sweden supplementation with either beta-alanine or placebo, and after an 11-days HIT block ( 9 sessions, $4 \times 4$ min), which followed supplementation. Carnosine was assessed via MR spectroscopy. Energy contribution during 90-s severe cycling was estimated from the $\mathrm{O}_{2}$ deficit. Biopsies from $m$. vastus lateralis were taken before and after the test.

Results Beta-alanine increased leg muscle carnosine $(32 \pm 13 \%, d=3.1)$. Buffering capacity and incremental cycling were unaffected, but during 90-s severe cycling, beta-alanine increased aerobic energy contribution $(1.4 \pm 1.3 \%, d=0.5)$, concurrent with reduced $\mathrm{O}_{2}$ deficit $(-5.0 \pm 5.0 \%, d=0.6)$ and muscle lactate accumulation $(-23 \pm 30 \%, d=0.9)$, while having no effect on $\mathrm{pH}$. Beta-alanine also enhanced motivation and perceived state during the HIT block. There were no between-group differences in adaptations to the training block, namely increased buffering capacity $(+7.9 \pm 11.9 \%, p=0.04, d=0.6$, $n=14)$ and glycogen storage $(+30 \pm 47 \%, p=0.04$, $d=0.5, n=16$ ).

Conclusions Beta-alanine did not affect buffering considerably, but has beneficial effects on severe exercise metabolism as well as psychological parameters during intense training phases.

Keywords Carnosine $\cdot$ Muscle buffering capacity $\cdot$ Block training $\cdot$ Glycogen

\section{Introduction}

Sporting events lasting between 60 and $\sim 240 \mathrm{~s}$; for example, in middle distance running, speed skating and alpine skiing, power output exceeds that corresponding to maximal oxygen uptake $\left(\mathrm{VO}_{2} \max \right)$ (Billat et al. 2009; de Koning et al. 2005; Ferguson 2010). For abrupt transitions at 
the start and at overall intensities in the severe domain (i.e., above the maximal oxygen uptake, $V_{2} \max$ ), aerobic energy provision is insufficient, and large amounts of ATP must be drawn from substrate-level phosphorylation, which entails increasing metabolite accumulation and is a cause of muscular fatigue (Jones et al. 2010). Thus, two options for improving performance in such events are enhancing aerobic contribution to power output (Demarle et al. 2001; Duffield et al. 2006; Weston et al. 1997) or improving the ability to counteract accumulation of fatigue-inducing metabolites (Messonnier et al. 2007).

High-intensity interval training (HIT) performed at an intensity near $V \mathrm{O}_{2}$ max effectively speeds $V \mathrm{O}_{2}$ on-kinetics and increases $V_{2}$ max and the critical power in trained persons (Billat et al. 2002; Breil et al. 2010; Demarle et al. 2001; Gross et al. 2007; Vanhatalo et al. 2008). These adaptations favor aerobic energy production in the severe exercise domain (Duffield et al. 2006; Weber and Schneider 2002). Further, HIT can improve skeletal muscle buffering capacity (Weston et al. 1997), minimizing the effects of accumulating protons, one suggested fatigue-inducing metabolite during severe exercise of a few minutes (Carr et al. 2011). In accord with this enhanced aerobic energy supply and curbed acidosis, improvements in severe exercise time-to-exhaustion (Weston et al. 1997) and performance (Gross et al. 2007; Stepto et al. 1999) have been shown following short blocks of HIT.

Oral supplementation with the amino acid beta-alanine leads to increases in muscle carnosine (Derave et al. 2007; Harris et al. 2006; Hill et al. 2007), a molecule which has positive effects on muscle function during exercise. For example, carnosine is a proton buffer in the physiological pH range (Abe 2000; Boldyrev 2000) and is therefore capable of lessening exercise-induced acidosis and acidosisinduced fatigue. As well, carnosine can counteract fatiguerelated events such as drops in $\mathrm{Ca}^{2+}$ release (shown in human type I fibers) and $\mathrm{Ca}^{2+}$ sensitivity of the contractile apparatus (in both fiber types) (Dutka et al. 2012), effects which are entirely independent of acidosis (as $\mathrm{pH}$ was fixed at 7.1 in the cited studies). While the addition of carnosine has little effect on maximal force, increases in $\mathrm{Ca}^{2+}$ sensitivity are important for maintaining force output when it is reduced to submaximal levels with fatigue. In accord with these proposed effects on buffering and muscle function, supplementation with high doses ( 10-20 times the normal daily intake) of isolated beta-alanine has previously been shown to improve exercise capacity in a 30 -s cycling sprint (Van Thienen et al. 2009), repeated 30-s isokinetic knee extensions (Derave et al. 2007) and cycling time-to-exhaustion at $110 \% V_{2} \max (\sim 2.5 \mathrm{~min})$ (Hill et al. 2007; Sale et al. 2011; Smith et al. 2009). Because carnosine returns slowly to baseline levels after beta-alanine supplementation is ceased (Baguet et al. 2009), effects of supplementation on exercise and training can be expected to last up to 3 weeks or longer. Thus, HIT and beta-alanine supplementation present two independent possibilities for positively affecting physiological determinants of exercise performance in the severe domain and lasting a few minutes.

In addition to individual effects of HIT and beta-alanine on determinants of severe exercise performance, there could be additional benefits of combining the two. For example, one time-effective strategy when implementing HIT comprises several consecutive days of demanding interval training sessions within a short training block (Breil et al. 2010; Gross et al. 2007; Laursen et al. 2002; Stolen et al. 2005; Storen et al. 2012). During such blocks, exceptionally large loads of high-intensity training are essential for achieving training adaptations, and there is evidence that greater training loads can be tolerated with supplemental beta-alanine (Hoffman et al. 2008a, b). This improved tolerance for training stressors could be related to various effects of muscle carnosine. Carnosine's ability to curb acidosis and oxidative stress (Begum et al. 2005) could quicken recovery between intense exercise bouts and between demanding training sessions, respectively. Further, carnosine could act to increase the threshold for neuromuscular fatigue, as shown by (Stout et al. 2007a, b) or counteract muscular fatigue, as implied by (Dutka and Lamb 2004; Dutka et al. 2012), thus allowing for a better-sustained training intensity or volume. Additionally, it is feasible that beta-alanine supplementation could also enhance training adaptations without affecting the training stimulus itself. For example, Bishop et al. (2010) showed reducing acidosis during HIT leads to greater mitochondrial adaptations in rat muscle, perhaps by promoting net protein synthesis or promoting upregulation of PGC- $1 \alpha$ and other genes regulating mitochondrial biogenesis. Whereas protection against acidosis in that study was achieved via supplementation with the extracellular buffer sodium bicarbonate, increasing intramuscular $\mathrm{pH}$ buffering, via carnosine, could benefit training adaptations in a similar manner. Thus, beta-alanine supplementation, by increasing the tolerance for intense training, could lead to more substantial training effects.

The aim of this two-part intervention study was to alter the physiological systems discussed above in ways that could improve severe exercise performance. We hypothesized that (1) HIT, by improving $V \mathrm{O}_{2}$ max and $V \mathrm{O}_{2}$ kinetics, would enhance aerobic energy contribution during severe cycling exercise; (2) beta-alanine supplementation, by increasing intramuscular carnosine, would improve buffering capacity and reduce $\mathrm{pH}$ disturbance, or otherwise dampen muscle fatigue during severe cycling exercise; and (3) prior supplementation with beta-alanine would allow for greater training load and better recovery during HIT, which would enhance benefits of training on physiological determinants of severe exercise performance. 


\section{Methods}

Design

This study employed a controlled, non-crossover design. The study timeline is displayed in Fig. 1. The study duration was 12 weeks. During an initial 2-week baseline period, medical screening and exercise test familiarization were achieved, and subjects began documenting their training. Thereafter, tests and measurements were performed at three time points (M1-M3), separated by two intervention phases. Phase 1 compared beta-alanine to a placebo; phase 2 assessed the effects of HIT in beta-alanine and placebo groups.

\section{Subjects and groups}

Seventeen males, who participated regularly in endurance, team, or combat sports, volunteered to participate in the study. Some participated in occasional recreational competitions (e.g., game sports, cycling, running, triathlon). Prior to a medical screening, they were informed of and signed informed written consent to all study procedures, which had been approved by the Ethical Review Board of the Canton of Bern, Switzerland. Based on $V \mathrm{O}_{2} \max (\mathrm{ml} / \mathrm{min} / \mathrm{kg})$ measurements attained during medical screening, matched pairs were randomly split into two groups. Subject characteristics are summarized in Table 1.

\section{Intervention}

In the first intervention phase, orally supplemented betaalanine was compared to a placebo in a double-blind fashion. For a period of 38 days, one group (BAL, $n=8$ ) consumed $3.2 \mathrm{~g}$ per day ( 4 doses of $800 \mathrm{mg}$ ) of purified beta-alanine (Harris et al. 2006), while the other group (PLA, $n=9$ ) consumed the same dosage of maltodextrin, which served as a placebo. Supplements were provided as 400-mg gel capsules (Pharma Futura SA, Grône, Switzerland), and subjects were instructed to take doses at each of the three main meals and before going to sleep. Placebo and beta-alanine were distributed by an impartial person, and neither investigators nor subjects could differentiate the two, either visually or by taste. During this phase, neither dietary intake nor training was specifically controlled. Subjects continued training as they were accustomed, and logged all training. Diet was not monitored.

In the second intervention phase, supplementation was discontinued and BAL and PLA completed the same HIT block. This was similar to that used by Breil et al. (2010) and consisted of nine HIT sessions performed within 11 days, performed and supervised in the lab. Rest was allowed on days 4 and 8 . Sessions were performed on a cycle ergometer and comprised a light 10-min warm-up followed by four 4-min intervals at the maximal sustainable power output. These intervals were intended to elicit heart rates (HR) of $90-95 \%$ of $\mathrm{HR}_{\max }$, which was monitored continuously (Polar Electro Oy, Kempele, Finland).

Fig. 1 Timeline of the study
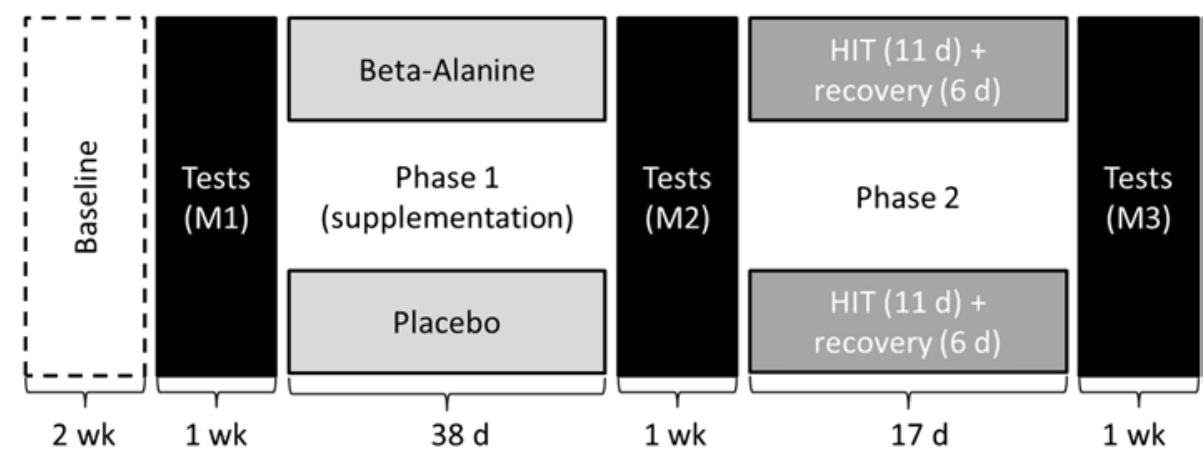

Table 1 Subject characteristics

\begin{tabular}{llllll}
\hline & Age (years) & Height $(\mathrm{cm})$ & Weight $(\mathrm{kg})$ & $V_{2} \max (\mathrm{ml} / \mathrm{kg} / \mathrm{min})$ & $\mathrm{pct.type} \mathrm{I}(\%)$ \\
\hline BAL $(n=8)$ & $32 \pm 8$ & $182 \pm 7$ & $77 \pm 7$ & $59 \pm 5$ & $69 \pm 7$ \\
PLA $(n=9)$ & $31 \pm 8$ & $180 \pm 7$ & $71 \pm 6$ & $61 \pm 4$ & $64 \pm 13$ \\
All $(n=17)$ & $31 \pm 8$ & $181 \pm 6$ & $74 \pm 7$ & $60 \pm 5$ & $67 \pm 11$ \\
Range (all) & $(23-45)$ & $(171-192)$ & $(64-85)$ & $(48-69)$ & $(48-88)$ \\
$p$ groups & 0.71 & 0.54 & 0.09 & 0.49 & 0.35 \\
\hline
\end{tabular}

Data presented as mean $\pm \mathrm{SD} . \mathrm{VO}_{2}$ max measured during medical screening. Percentage of type I muscle fibers (pct. type I) averaged across M1 and $\mathrm{M} 2$, as values from these time points did not differ $(p=0.27)$ 
Intervals were separated by $3 \mathrm{~min}$ of light cycling (no greater than $40 \%$ PPO). Subjects from both groups trained together. Subjects were encouraged to increase training power output as much as possible throughout the training block. Subjects began the block in a normal state of recovery. Following the ninth HIT session, subjects were afforded 6 days of recovery, with the instruction to train only lightly so as to promote regeneration. This was confirmed by reviewing their training logs. Data gathered during the HIT sessions included subjective state and motivation (on a 0-10 scale) prior to warm-up, power and ratings of perceived exertion (RPE) for each interval, and blood lactate (BLa) after the first and fourth intervals and HR continually throughout the session.

\section{Tests/measurements}

Body weight was taken at each time point (M1-M3) on a Quattrojump force plate (Kistler Instruments, Winterthur, Switzerland) and body fat percentage was estimated from seven skinfolds according to regression described by Jackson and Pollock (1978). As well, the following measurements were made at each time point (see Fig. 1).

\section{$M R S$}

Muscle carnosine concentration ([carn]) was determined in $m$. tibialis anterior, $m$. gastrocnemius, $m$. vastus intermedius, and $m$. vastus lateralis using single voxel $1 \mathrm{H}-\mathrm{MR}$ spectroscopy on a 3 Tesla MR system (TRIO, SIEMENS Erlangen, Germany). Following the acquisition of a localizer series, a high-resolution imaging series of the calf or thigh (Fast spin echo, echo train 19, TR $=2,660 \mathrm{~ms}$, TE $13 \mathrm{~ms}$, slice $4 \mathrm{~mm}$, pixel $0.625 \times 0.625 \mathrm{~mm}$ ) was acquired for the definitive placement of the MRS voxel. A standard flexible surface coil was used to obtain the high-resolution images and subsequent PRESS spectra ("point-resolvedspectroscopy", TR $=3,000 \mathrm{~ms}$, TE $=30 \mathrm{~ms}$ ). The default voxel size was set to $18 \times 18 \times 30 \mathrm{~mm}$ (Left-Right, Anterior-Posterior, Head-Feet), but was adjusted in LR and AP direction in case of small cross section of the muscles or fatty infiltrations. Voxels were positioned with an accuracy of a few millimeters to minimize effects of variations in dipolar coupling effects (depending on the pennation angle) and tissue composition along the muscles. During the measurement, the leg was fixed in all three directions by a custom-made fixation device. Ninety-six scans with the central frequency at the carnosine- $\mathrm{H}_{2}$ position (8.0 ppm, PRESS sequence of the vendor adapted) were followed by an unsuppressed water scan $(n=1)$ with the central frequency shifted to the water position to correct for the chemical shift displacement and to acquire exactly the same voxel for the metabolites and the water standard.
Absolute quantification of [carn] was based on an unsuppressed water spectrum as described elsewhere (Stellingwerff et al. 2012), using relaxation values from literature (Ozdemir et al. 2007).

\section{Incremental cycling test}

An incremental cycling test to exhaustion was performed on an Ergometrics 800S cycle ergometer (ergoline GmbH, Bitz, Germany) for the determination of $V_{2}$ max, peak power output (PPO), $\mathrm{HR}_{\max }$, maximal blood lactate concentration $\left(\mathrm{BLa}_{\max }\right)$ and $\mathrm{PO}$ at the second ventilatory threshold $\left(\mathrm{PVT}_{2}\right)$. Beginning at $70 \mathrm{~W}$, power was increased stepwise by $30 \mathrm{~W}$ every $2 \mathrm{~min}$, until volitional exhaustion or a pedaling cadence dropped below $60 \mathrm{rpm}$ for three seconds. During the last $15 \mathrm{~s}$ of each stage and at exhaustion, BLa was measured at the finger (Biosen C-line sport, EKF-diagnostic $\mathrm{GmbH}$, Barleben/Magdeburg, Germany). Breath-bybreath respiratory data were collected using an Oxycon Pro (Erich Jaeger GmbH, Höchberg, Germany). HR was measured continuously. $\mathrm{VO}_{2}$ max was taken as the highest 30-s average of breath-by-breath data and confirmed when the corresponding respiratory exchange ratio was at least 1.1 and blood lactate was at least $7.5 \mathrm{mmol} / \mathrm{l}$. PPO was interpolated from the average $\mathrm{P} / \mathrm{t}$ slope (i.e., $15 \mathrm{~W} / \mathrm{min}$ ) and time point at exhaustion. $\mathrm{BLa}_{\max }$ was taken at exhaustion. $\mathrm{P}$ $\mathrm{VT}_{2}$ was identified by two independent investigators as the interpolated $\mathrm{PO}$ corresponding to the second breakpoint in the respiratory equivalents of $\mathrm{O}_{2}$ and $\mathrm{CO}_{2}$, i.e., minute ventilation $\left(V_{\mathrm{e}}\right) / V \mathrm{O}_{2}$ and $V_{\mathrm{e}} / V \mathrm{CO}_{2}$, respectively (Dekerle et al. 2003).

\section{Fixed power test (FPT)}

At least $24 \mathrm{~h}$ later, a fixed power, fixed duration (90 s) cycling test was performed using the equipment described above, for assessing oxygen deficit and proportions of aerobic and anaerobic energy contribution. After a 10-min warm-up at $40 \% \mathrm{PPO}_{\mathrm{M} 1}$, subjects cycled at $50 \mathrm{~W}$ and $60 \mathrm{rpm}$ for $3 \mathrm{~min}$, to allow $V_{2}$ to level off (baseline phase). The baseline power output was chosen because it is the lowest at which the Ergoline can provide continuous resistance at $60 \mathrm{rpm}$. Thereafter, cadence was increased to $105 \mathrm{rpm}$ and power was adjusted to $110 \% \mathrm{PPO}_{\mathrm{M} 1}$ within approximately $3 \mathrm{~s}$. This was maintained for $90 \mathrm{~s}$. Absolute power output remained the same for M1-M3 (40 and $110 \%$ of PPO attained at M1). Blood lactate was measured $30 \mathrm{~s}$ before, $15 \mathrm{~s}$ after and $4 \mathrm{~min}$ after the 90 -s test. The cadence during the test was chosen to ensure that subjects could pedal smoothly and complete the exercise task with minimal upper body motion. $V \mathrm{O}_{2}$ peak in the FPT was defined as the highest 15 -s average of breath-by-breath data. 
Oxygen deficit was taken as the difference between $\mathrm{O}_{2}$ consumption during the 90-s test and the estimated $\mathrm{O}_{2}$ demand (Bangsbo et al. 1990). $\mathrm{O}_{2}$ consumption was the area under the curve of gross $V \mathrm{O}_{2}$ between 0 and 90 s (i.e., mean $\left.V \mathrm{O}_{2} \cdot 1.5 \mathrm{~min}\right) . \mathrm{O}_{2}$ demand at $110 \%$ PPO was estimated by interpolating data from the most recent incremental test (using stages prior to plateau in $V \mathrm{O}_{2}$ only) and correcting the y-intercept based on steady-state $V \mathrm{O}_{2}$ during the warm-up prior to the FPT. The following equation was used for estimating $\mathrm{O}_{2}$ demand:

$\mathrm{O}_{2}$ demand $=\left[m \cdot \mathrm{PO}_{110 \%}+\left(\mathrm{b}-m \cdot \mathrm{PO}_{40} \%\right)\right] \cdot 1.5 \mathrm{~min}$

where $m$ is the slope of the $V \mathrm{O}_{2} / \mathrm{PO}$ relationship $(\mathrm{ml} /$ $\mathrm{min} / \mathrm{W}$ ) established from the most recent incremental test, $\mathrm{b}$ is the steady-state $V \mathrm{O}_{2}(\mathrm{ml} / \mathrm{min})$ averaged over the second half of the warm-up preceding the 90-s test, and $\mathrm{PO}_{110} \%$ and $\mathrm{PO}_{40} \%$ are the power outputs (W) applied during test and warm-up, respectively. Finally, the percentage of aerobic energy contribution was calculated as $\mathrm{O}_{2}$ consumption/ $\mathrm{O}_{2}$ demand $100 \%$. In our lab, $\mathrm{CV}$ in this test for $\mathrm{O}_{2}$ consumption, $\mathrm{O}_{2}$ deficit, and aerobic energy contribution are $2 \%(95 \% \mathrm{CI} \pm 88 \mathrm{ml}), 3 \%(95 \% \mathrm{CI} \pm 115 \mathrm{ml})$, and $2 \%$ (95\% CI \pm 1.1 percentage points), respectively (Märzendorfer 2011).

\section{Biopsy analyses}

In combination with the 90-s FPT, two muscle biopsies from $m$. vastus lateralis were taken. Prior to warm-up, two incisions were made under local anesthesia induced with Lidocaine, approximately $1 \mathrm{~cm}$ apart in the mid-thigh portion of $m$. vastus lateralis of the right leg, and the first (pre-exercise) biopsy was extracted using a Bergstrom needle (1975). A second (post-exercise) biopsy was extracted using a Pro-Mag 2.2 automatic biopsy instrument (MD Tech, Gainsville, FL, USA) exactly $15 \mathrm{~s}$ after completion of the FPT. Both biopsies were immediately frozen in isopentane cooled by liquid nitrogen, then preserved in liquid nitrogen until further analysis.

For M1 and M2 only, cross-sectional slices $(12 \mu \mathrm{m})$ were stained for determining muscle fiber-type composition using procedures described by Billeter et al. (1980). Samples were pre-incubated at $\mathrm{pH} 4.75$ instead of $\mathrm{pH} 4.35$, as this produced better contrast in pilot stains. Stained samples were photographed with $20 \times$ magnification (ColorView 3U CCD Color Camera in a Leica DMRB light microscope). First, fibers were visually classified as type I, IIA or IIX. Then, to determine fiber-specific cross-sectional area $(\mathrm{CSA})$, photos were overlaid with a $30 \times 30 \mu \mathrm{m}$ grid using cell^ ${ }^{\wedge}$ software (version 3.4 , Olympus Soft Imaging Solutions, $\mathrm{GmbH}$ ), and intersection points on classified type I and IIA and IIX fibers showing no ellipticity were counted manually, according to Weibel (1979). In all,
$153 \pm 104$ and $128 \pm 62$ fibers per subject were analyzed for M1 and M2, respectively.

For M1-M3, portions of resting and post-exercise biopsies were freeze-dried, dissected under a microscope until freed from blood and connective tissue, and weighed for analysis of muscle $\mathrm{pH}$, buffering capacity, muscle lactate, glycogen, and enzyme activities (see below).

One portion of freeze-dried muscle (1-9 mg) was designated for determination of muscle $\mathrm{pH}$ and buffering capacity, based on the methods of Bishop et al. (2008). In short, muscle was homogenized by hand on ice in a $10-\mathrm{mM} \mathrm{NaF}$ solution at a dilution of $30-\mathrm{mg}$ muscle/ml solution. Twentyfive- or $30-\mu 1$ portions were transferred to Eppendorf tubes, vortexed, and warmed to $37{ }^{\circ} \mathrm{C}$ on a Thermomixer (Vadaux-Eppendorf, Basel, Switzerland) for measurement of $\mathrm{pH}$ using a microelectrode (MI-410, Microelectrodes Inc., USA) connected to a pH meter (Model 320, MettlerToledo, USA) double-calibrated at $\mathrm{pH} 7.0$ and 4.01. After initial $\mathrm{pH}$ determination, solutions from pre-exercise samples were titrated with $10-\mathrm{mM} \mathrm{HCl}$ until $\mathrm{pH}$ decreased to 6.3; $\mathrm{pH}$ was measured after each $2 \mu \mathrm{l}$ addition of $\mathrm{HCl}$, and the mean slope was calculated from the serial $\mathrm{pH}$ measurements and normalized to express muscle buffering capacity in terms of $\mathrm{mmol} \mathrm{H}^{+} / \mathrm{kg}$ dry muscle/pH unit.

Another portion $(0.7-6.8 \mathrm{mg}$ ) was submerged in $0.4-\mathrm{M}$ $\mathrm{HClO}_{4}$ on ice and broken into small pieces by hand to extract metabolites. After $20 \mathrm{~min}$, the solution was neutralized using 2-M $\mathrm{KHCO}_{3}$ and centrifuged for $10 \mathrm{~s}$. Muscle lactate was analyzed in the supernatant by a fluorometric enzymatic method (Lowry and Passonneau 1972).

Another portion $(0.5-8 \mathrm{mg})$ was homogenized in $400 \mu \mathrm{l} / \mathrm{mg} 0.1-\mathrm{M}$ phosphate buffer at $\mathrm{pH} 7.7$ with $0.5 \%$ bovine serum albumin. Ten $\mu 1$ homogenate was mixed with $40 \mu 11.5-\mathrm{M} \mathrm{HCl}$ and incubated for $1.5 \mathrm{~h}$ at $100^{\circ} \mathrm{C}$ to break down glycogen into glycosyl units. After cooling, glycogen concentration was quantified via glucose by a fluorometric enzymatic method (Lowry and Passonneau 1972). Separately, portions of the same homogenate were used for determining activities of citrate synthase (CS) and phosphofructokinase (Pfk), using a fluorometric enzymatic method (Lowry and Passonneau 1972).

\section{Monitoring tools}

Throughout the study, subjects kept a training log including total exercise time and perceived intensity ( $0-10$ scale) for calculation of training volume and load according to Foster et al. (2001). Logged training sessions were categorized into intensity zones I, II, and III based on reported session RPE (Seiler and Kjerland 2006), and training descriptives were evaluated based on these zones. Subjects also documented their dose-by-dose intake of the supplement in their training logs, from which supplement compliance was quantified. 
Data analysis

All results are reported as mean $\pm \mathrm{SD}$. The main variables were initially assessed for interactions using $2 \times 3$ (group time) ANOVA (SPSS, Version 20, IBM). Withingroup changes, as well as changes in the pooled cohort, were assessed thereafter (post hoc) across each intervention phase using repeated-measures $t$ tests. Additionally, independent $t$ tests on individual deltas values were performed. For $t$ tests, no correction for multiple comparisons was made (Hopkins et al. 2009; Perneger 1998). For some variables, changes were compared between phases using repeated-measures $t$ tests. Training data from subjects' training $\operatorname{logs}$ and HIT sessions were compared between groups using independent $t$ tests. The alpha level for significance was set at 0.05 . Cohen's effect sizes $(d)$ were calculated as the ratio of mean change to the standard deviation of initial values. Finally, observed power of the ANOVA (calculated using SPSS, $\alpha=0.05$ ) are reported for the main variables.

\section{Results}

All subjects remained in the study through M2. One subject from BAL dropped out of the study between M2 and M3, while another from BAL could not complete the incremental test at M3 due to sickness. Accordingly, effects across phase 2 were analyzed with a reduced $n$ in BAL, as noted in the text and tables. There were no changes in bodyweight or body composition for either group at any time point during the study (all $p>0.14$ ).

Supplement compliance and muscle carnosine

According to subjects' documentation, supplement compliance was $99.4 \pm 1.7 \%$ in BAL and $99.9 \pm 0.2 \%$ in PLA. Due to limited availability of the MR, MRS could be performed on only 14 subjects. Prior to supplementation, there were differences in mean [carn] between the four measured muscles, namely $m$. gastroc. $>(p<0.01)$ m. vast. lat. $>(p=0.12) m$. tib. ant. $>(p<0.01) m$. vast. int. In BAL, significant increases in all four muscles $(+24$ to $49 \%$ ) occurred with supplementation (Table 2). Percent changes in [carn] with beta-alanine supplementation were not uniform in the four muscles, as can be seen in Table 2. Between M1 and M2, the relative increase in $m$. vast. int. $(+49 \pm 27 \%)$ was significantly greater than in m. gastroc. $(+24 \pm 14 \%)$ and $m$. vast. lat. $(+25 \pm 10 \%)$. As well, increases in $m$. tib. ant $(+37 \pm 12 \%)$ were significantly greater than in $m$. gastroc. and $m$. vast. lat. (all $p$ values from repeated-measures $t$ tests $<0.05$ ). Although [carn] of BAL dropped significantly between M2 and M3 in $m$. vast. int. $(p=0.01)$ and $m$. vast. lat. $(p=0.04)$, it remained $19-33 \%$ higher at M3 than at M1 $(p \leq 0.01)$ in all muscles. There were no changes in [carn] at any time in PLA $(n=7)$, and the group time interaction was significant $(p$ from ANOVA $<0.01$ ) for all muscles. Deltas at M2 and M3 (at each time point compared to M1) were significantly greater for BAL than PLA in all muscles $(p<0.01)$, except for $m$. vast.int. at M3 $(p=0.09)$. Observed power for [carn] in the various muscles ranged from 0.97 to 1.00 .

\section{Muscle histochemistry}

There were no significant differences in fiber-type distribution between groups at M1 $(p>0.33)$ or M2 $(p>0.13)$ and no changes occurred in either group between M1 and M2 ( $p$ from ANOVA 0.66). On average, subjects had $66 \pm 12 \%$ (range $48-89 \%$ ) type I, $26 \pm 12 \%$ (4.6-52\%) type IIA, and $7.3 \pm 7.8 \%(0.0-26 \%)$ type IIX muscle fibers. There was no interaction effect for muscle fiber CSA ( $p$ from ANOVA 0.25 , observed power 0.40). However, CSA increased significantly in BAL in type I fibers $(+16 \pm 12 \%, p=0.01)$, whereas changes in type IIA $(p=0.18)$ and IIX $(p=0.16)$ fibers were not significant. There were no changes in CSA for PLA. Table 3 displays CSA data after removing outliers (values or deltas greater than two standard deviations from the mean).
Table 2 Changes in muscle carnosine by group

\footnotetext{
Data presented as mean $\pm \mathrm{SD}$

(n)

$* p<0.05, * * p<0.01$ from repeated-measures $t$ test, compared to M1. ${ }^{\S} p<0.05$, compared to M2. ${ }^{\#} p<0.05$ compared to BAL at same time point
}

\begin{tabular}{rlcll}
\hline \multicolumn{5}{l}{ Muscle carnosine content (mmol/kg wet weight) } \\
\cline { 2 - 5 } & m. tib. ant. & m. gastroc. & m. vast. int. & m. vast. lat. \\
\hline BAL & & & \\
M1 & $6.9 \pm 0.8(7)$ & $8.8 \pm 1.0(7)$ & $5.6 \pm 1.1(7)$ & $7.4 \pm 1.6(7)$ \\
M2 & $9.4 \pm 0.8(7)^{* *}$ & $10.8 \pm 1.1(7)^{* *}$ & $8.2 \pm 1.1(7)^{* *}$ & $9.2 \pm 1.4(7)^{* *}$ \\
M3 & $8.8 \pm 1.1(6)^{* *}$ & $10.5 \pm 1.1(6)^{* *}$ & $7.2 \pm 1.0(6)^{* * \S}$ & $8.6 \pm 1.2(6)^{* * \S}$ \\
PLA & & & & \\
M1 & $6.8 \pm 1.1(7)$ & $9.6 \pm 1.2(7)$ & $5.7 \pm 1.3(7)$ & $7.1 \pm 0.7(7)$ \\
M2 & $7.1 \pm 0.9(7)^{\#}$ & $9.2 \pm 1.6(7)^{\#}$ & $6.1 \pm 1.0(7)^{\#}$ & $7.2 \pm 1.0(7)^{\#}$ \\
M3 & $6.9 \pm 1.1(7)^{\#}$ & $9.2 \pm 1.7(7)$ & $6.6 \pm 0.9(7)$ & $7.0 \pm 1.0(7)^{\#}$ \\
\hline
\end{tabular}


Table 3 Muscle fiber cross-sectional area by fiber type

\begin{tabular}{rllll}
\hline & All fibers & Type I & Type IIA & Type IIX \\
\hline BAL & & & & \\
M1 & $6,231 \pm 967(6)$ & $6,034 \pm 1,015(6)$ & $6,779 \pm 1,087(6)$ & n.a. \\
M2 & $7,014 \pm 731(6)^{*}$ & $6,946 \pm 724(6)^{*}$ & $7,330 \pm 1,177(6)$ & \\
PLA & & & & \\
M1 & $6,576 \pm 1,284(6)$ & $6,403 \pm 1,623(6)$ & $7,459 \pm 1,419(6)$ & $4,707 \pm 1,125(3)$ \\
M2 & $6,123 \pm 657(6)$ & $5,923 \pm 620(6)$ & $6,713 \pm 1,085(6)$ & $6,418 \pm 1,245(3)$ \\
\hline
\end{tabular}

Values from the only two subjects in BAL having type IIX fibers at both time points were considered outliers. Data presented as mean \pm SD $(n)$ $* p \leq 0.05$ from repeated-measures $t$ test, compared to M1

Table 4 Parameters from maximal incremental cycling test

Data presented as mean $\pm \mathrm{SD}$

(n)

Bold values indicate statistical significance $(p<0.05)$

$P P O$ peak power output, $B L a_{\max }$ maximal blood lactate, $P V T_{2}$ power at second ventilatory threshold

\begin{tabular}{|c|c|c|c|c|}
\hline & $V \mathrm{O}_{2} \max (\mathrm{ml} / \mathrm{min} / \mathrm{kg})$ & $\mathrm{PPO}(\mathrm{W})$ & $\mathrm{BLa}_{\max }(\mathrm{mmol} / \mathrm{l})$ & $\mathrm{PVT}_{2}(\mathrm{~W})$ \\
\hline \multicolumn{5}{|l|}{ BAL } \\
\hline $\mathrm{T} 1$ & $57.4 \pm 4.0(8)$ & $332 \pm 30(8)$ & $12.0 \pm 3.6(8)$ & $242 \pm 24(8)$ \\
\hline$p$ time & 0.37 & 0.16 & 0.23 & 0.40 \\
\hline $\mathrm{T} 2$ & $58.2 \pm 4.9(8)$ & $342 \pm 40(8)$ & $12.5 \pm 2.6(8)$ & $246 \pm 25(8)$ \\
\hline$p$ time & 0.92 & 0.48 & 0.35 & 0.18 \\
\hline $\mathrm{T} 3$ & $59.8 \pm 4.2(6)$ & $362 \pm 27(6)$ & $13.4 \pm 3.4(6)$ & $265 \pm 14(6)$ \\
\hline \multicolumn{5}{|l|}{ PLA } \\
\hline $\mathrm{T} 1$ & $58.1 \pm 4.3(9)$ & $322 \pm 49(9)$ & $11.3 \pm 1.6(9)$ & $234 \pm 36(9)$ \\
\hline$p$ time & 0.76 & 0.18 & 0.33 & 0.06 \\
\hline $\mathrm{T} 2$ & $57.8 \pm 3.9(9)$ & $326 \pm 43(9)$ & $10.7 \pm 2.5(9)$ & $246 \pm 40(9)$ \\
\hline$p$ time & 0.18 & $<0.01$ & $<0.01$ & 0.41 \\
\hline $\mathrm{T} 3$ & $59.6 \pm 4.5(9)$ & $342 \pm 44(9)$ & $13.2 \pm 2.3(9)$ & $253 \pm 31(9)$ \\
\hline \multicolumn{5}{|c|}{ Group time ANOVA } \\
\hline$p$ & 0.40 & 0.29 & 0.18 & 0.84 \\
\hline Power & 0.20 & 0.26 & 0.34 & 0.07 \\
\hline \multicolumn{5}{|c|}{ Intergroup $p$ on deltas } \\
\hline $\mathrm{T} 1-\mathrm{T} 2$ & 0.39 & 0.43 & 0.14 & 0.31 \\
\hline $\mathrm{T} 2-\mathrm{T} 3$ & 0.32 & 0.13 & 0.06 & 0.93 \\
\hline
\end{tabular}

Maximal incremental performance

Values from the incremental test are presented in Table 4. There was no interaction effect ( $p$ from ANOVA $\geq 0.40$ ), and there were no effects of supplementation within either group between M1 and M2. There were, however, small but significant increases for the cohort as a whole for PPO $(+2.2 \pm 3.9 \%, p=0.05, d=0.2, n=17)$ and $\mathrm{PO}$ at $\mathrm{VT}_{2}$ $(+3.7 \pm 6.9 \%, p=0.04, d=0.3, n=17)$, but not $V \mathrm{O}_{2} \max$. In addition, between M2 and M3 there was a small significant increase for the entire cohort on PPO $(+3.7 \pm 4.2 \%$, $p=0.01, d=0.3, n=15)$ with no change in $V \mathrm{O}_{2} \max$. Repeated-measures $t$ test on the PPO deltas revealed that changes across the HIT phase were not different from those across the supplementation phases ( $p=0.56, n=15)$. Between M2 and M3, there was no interaction effect on $\mathrm{BLa}_{\max }$ ( $p$ from ANOVA 0.18); however, there was an increase in PLA $(+18 \pm 10 \%, p<0.01, d=1.0, n=9)$ but not in BAL $(+5.1 \pm 13.0 \%, p=0.35, d=0.3, n=8)$.

Physiological determinants of severe exercise performance

Data from the FPT are displayed in Table 5. There were no significant interactions for any FPT parameters. However, following supplementation, $\mathrm{O}_{2}$ deficit was reduced $(-5.0 \pm 5.0 \%, p=0.02, d=0.6, n=8)$ and aerobic energy contribution increased $(1.4 \pm 1.3 \%, p=0.02$, $d=0.5, n=8$ ) in BAL, whereas no change occurred in either parameter in PLA. Blood lactate 4-min post-exercise $(-8.2 \pm 10.5 \%, p=0.06, d=0.6, n=8)$ and postexercise muscle lactate $(-21 \pm 29 \%, p=0.06, d=0.8$, $n=8$ ) displayed strong tendencies for being decreased in BAL only, and there was a significant decrease in exercise-induced muscle lactate accumulation in BAL 
Table 5 Metabolic mechanisms during severe intensity exercise

\begin{tabular}{|c|c|c|c|c|c|}
\hline & $\mathrm{O}_{2}$ deficit $(\mathrm{ml})$ & E aerobic $(\%)$ & $\mathrm{BLa} 4^{\prime}(\mathrm{mmol} / \mathrm{l})$ & MLa (mmol/kg d.w.) & $\Delta \mathrm{MLa}(\%)$ \\
\hline \multicolumn{6}{|l|}{ BAL } \\
\hline $\mathrm{T} 1$ & $2,587 \pm 199(8)$ & $64.8 \pm 2.6(8)$ & $8.8 \pm 1.1(8)$ & $51 \pm 17(8)$ & $47 \pm 16(8)$ \\
\hline$p$ time & 0.02 & 0.02 & 0.06 & 0.06 & 0.05 \\
\hline $\mathrm{T} 2$ & $2,461 \pm 271(8)$ & $66.1 \pm 3.2(8)$ & $8.0 \pm 1.2(8)$ & $37 \pm 10(8)$ & $33 \pm 12(8)$ \\
\hline$p$ time & 0.54 & 0.60 & 0.77 & 0.26 & 0.30 \\
\hline T3 & $2,542 \pm 217(7)$ & $65.7 \pm 2.2(7)$ & $8.2 \pm 1.9(7)$ & $43 \pm 13(7)$ & $39 \pm 14(7)$ \\
\hline \multicolumn{6}{|l|}{ PLA } \\
\hline $\mathrm{T} 1$ & $2,210 \pm 488(9)$ & $68.1 \pm 5.1(9)$ & $9.0 \pm 1.0(9)$ & $43 \pm 31(8)$ & $39 \pm 31(8)$ \\
\hline$p$ time & 0.74 & 0.99 & 0.38 & 0.81 & 0.87 \\
\hline $\mathrm{T} 2$ & $2,170 \pm 417(9)$ & $68.0 \pm 4.0(9)$ & $8.7 \pm 0.9(9)$ & $47 \pm 14(9)$ & $41 \pm 13(9)$ \\
\hline$p$ time & 1.00 & 0.88 & 0.02 & 0.51 & 0.46 \\
\hline $\mathrm{T} 3$ & $2,170 \pm 366(9)$ & $67.9 \pm 3.3(9)$ & $8.0 \pm 0.7(9)$ & $40 \pm 15(9)$ & $34 \pm 15(8)$ \\
\hline \multicolumn{6}{|c|}{ Group time ANOVA } \\
\hline$p$ & 0.91 & 0.71 & 0.25 & 0.58 & 0.59 \\
\hline Power & 0.06 & 0.10 & 0.29 & 0.13 & 0.13 \\
\hline \multicolumn{6}{|c|}{ Intergroup $p$ on deltas } \\
\hline $\mathrm{T} 1-\mathrm{T} 2$ & 0.51 & 0.31 & 0.43 & 0.18 & 0.20 \\
\hline $\mathrm{T} 2-\mathrm{T} 3$ & 0.71 & 0.84 & 0.07 & 0.22 & 0.20 \\
\hline
\end{tabular}

Data presented as mean $\pm \mathrm{SD}(n)$. Cycling test comprised $90 \mathrm{~s}$ at $110 \% \mathrm{PPO}$

Bold values indicate statistical significance $(p<0.05)$

$E$ aerobic aerobic contribution to energy, $B L a 4^{\prime}$ blood lactate 4-min post-exercise, $M L a$ muscle lactate, $\triangle M L a$ muscle lactate accumulation pre- to post-exercise, $\tau$ on time constant of $\mathrm{VO}_{2}$ on-kinetics

Table 6 Muscle $\mathrm{pH}$ and buffering capacity

\begin{tabular}{llll}
\hline & $\mathrm{pH}$ pre-exercise & $\mathrm{pH}$ post-exercise & Buffering capacity \\
\hline BAL & & & \\
T1 & $7.01 \pm 0.05(8)$ & $6.76 \pm 0.07(8)$ & $180 \pm 21(8)$ \\
$p$ time & 0.27 & 0.30 & 0.54 \\
T2 & $7.06 \pm 0.11(8)$ & $6.80 \pm 0.07(8)$ & $174 \pm 19(8)$ \\
$p$ time & 0.71 & 0.39 & 0.57 \\
T3 & $7.02 \pm 0.10(7)$ & $6.82 \pm 0.12(7)$ & $184 \pm 20(5)$ \\
PLA & & & \\
T1 & $7.03 \pm 0.13(9)$ & $6.77 \pm 0.10(9)$ & $184 \pm 15(9)$ \\
$p$ time & 0.59 & 0.06 & 0.20 \\
T2 & $7.07 \pm 0.14(9)$ & $6.89 \pm 0.18(9)$ & $172 \pm 23(9)$ \\
$p$ time & 0.45 & 0.94 & $\mathbf{0 . 0 1}$ \\
T3 & $7.02 \pm 0.07(9)$ & $6.88 \pm 0.15(9)$ & $186 \pm 25(9)$ \\
Group time ANOVA & & & \\
$p$ & 0.92 & 0.41 & 0.85 \\
Power & 0.06 & 0.19 & 0.07 \\
Intergroup $p$ on deltas & & & \\
T1-T2 & 0.94 & 0.25 & 0.61 \\
T2-T3 & 0.59 & 0.57 & \\
\hline
\end{tabular}

following supplementation $(-23 \pm 30 \%, p=0.05$, $d=0.9, n=8$ ), but not PLA. Between M2 and M3, effects seen for these parameters in BAL diminished non-significantly toward pre-supplementation values, such that there were no significant differences between M1 and M3. 
Table 7 Muscle glycogen content

\begin{tabular}{lll}
\hline & $\begin{array}{l}\text { Glycogen pre- } \\
\text { exercise (mmol/ } \\
\text { kg d.w.) }\end{array}$ & $\begin{array}{l}\text { Glycogen post- } \\
\text { exercise (mmol/ } \\
\text { kg d.w.) }\end{array}$ \\
\hline BAL & & \\
T1 & $525 \pm 131(8)$ & $409 \pm 67(8)$ \\
$p$ time & 0.57 & 0.92 \\
T2 & $488 \pm 113(8)$ & $406 \pm 120(8)$ \\
$p$ time & 0.05 & $\mathbf{0 . 0 2}$ \\
T3 & $612 \pm 178(7)$ & $545 \pm 159(7)$ \\
PLA & & \\
T1 & $559 \pm 94(9)$ & $384 \pm 138(9)$ \\
$p$ time & 0.33 & 0.41 \\
T2 & $482 \pm 203(9)$ & $340 \pm 50(9)$ \\
$p$ time & 0.31 & $\mathbf{0 . 0 1}$ \\
T3 & $547 \pm 90(9)$ & $481 \pm 117(9)$ \\
Group time ANOVA & & \\
$p$ & 0.63 & 0.77 \\
Power & 0.12 & 0.09 \\
Intergroup $p$ on deltas & & 0.51 \\
T1-T2 & 0.70 & 0.92 \\
T2-T3 & 0.56 & \\
\hline
\end{tabular}

Data presented as mean \pm SD $(n)$

Bold values indicate statistical significance $(p<0.05)$

There were no interaction or time effects of supplementation or HIT on post-exercise muscle $\mathrm{pH}$ in BAL or PLA, or on exercise-induced $\mathrm{pH}$ change (Table 6). There was no interaction effect on buffering capacity. However, although muscle buffering capacity was not affected by supplementation in either group or in the pooled cohort, this increased significantly in the pooled cohort in response to HIT $(+7.9 \pm 11.9 \%, p=0.04, d=0.6, n=14)$. The change in buffering capacity in the HIT phase was significantly greater than during the supplementation phase (repeatedmeasures $t$ test on deltas: $p=0.03$ ).

There were no intragroup or interaction effects on resting glycogen or glycogen usage during the FPT. However, resting muscle glycogen increased in the pooled cohort in response to HIT ( $+30 \pm 47 \%, p=0.04, d=0.5, n=16$ ), with no differences in the response between groups. Similarly, post-exercise glycogen was higher after HIT, regardless of group, $(+41 \pm 35 \%, p<0.01, d=1.4, n=16)$, but no significant effect was apparent on net glycogen usage during the FPT. Glycogen data are presented in Table 7.

There were no changes in CS activity during the study and no interaction effect on PFK activity. However, there was a decrease in Pfk activity following supplementation in BAL $(-18 \pm 17 \%, p=0.03, d=1.4, n=8)$, but not in PLA (Table 8).
Table 8 Muscle enzyme activity

\begin{tabular}{lll}
\hline & $\begin{array}{l}\text { CS }(\mathrm{mmol} \mathrm{NADH} / \\
\mathrm{kg} \mathrm{d} . \mathrm{w} . / \mathrm{min})\end{array}$ & $\begin{array}{l}\mathrm{Pfk}(\mathrm{mmol} \mathrm{NAD} \\
\mathrm{kg} \mathrm{d} . \mathrm{w} . / \mathrm{min})\end{array}$ \\
\hline BAL & & \\
$\mathrm{T} 1$ & $20.95 \pm 6.63(8)$ & $13.21 \pm 7.01(8)$ \\
$p$ time & 0.50 & $\mathbf{0 . 0 3}$ \\
T2 & $19.27 \pm 4.89(8)$ & $10.31 \pm 4.86(8)$ \\
$p$ time & 0.90 & 0.76 \\
T3 & $21.06 \pm 6.60(6)$ & $10.30 \pm 4.06(7)$ \\
PLA & & \\
T1 & $18.65 \pm 2.29(9)$ & $13.87 \pm 6.51(9)$ \\
$p$ time & 0.88 & 0.58 \\
T2 & $18.28 \pm 6.55(9)$ & $14.77 \pm 7.92(9)$ \\
$p$ time & 0.28 & 0.87 \\
T3 & $21.14 \pm 6.31(9)$ & $15.05 \pm 8.46(9)$ \\
Group time ANOVA & & \\
$p$ & 0.57 & 0.12 \\
Power & 0.13 & 0.42 \\
Intergroup $p$ on deltas & & \\
T1-T2 & 0.71 & 0.07 \\
T2-T3 & 0.42 & \\
\hline
\end{tabular}

Data presented as mean $\pm \mathrm{SD}(n)$

Bold values indicate statistical significance $(p<0.05)$

$C S$ citrate synthase, $P f k$ phosphofructokinase

Normal training and HIT block

There were no changes in training habits of either BAL or PLA across the supplementation period, nor were there any differences between groups during baseline or supplementation. Compared to the supplementation period, there were significant increases during the HIT block (pooled data, $n=16$, no interaction or intergroup differences) in the weekly number of training sessions performed in zone III (from $0.8 \pm 0.9$ to $3.8 \pm 0.3$ ), weekly zone III training volume (from $62 \pm 84$ to $142 \pm 41 \mathrm{~min}$ ) and in the typical session RPE (from $7.5 \pm 0.5$ to $8.9 \pm 0.7$ ) for zone III sessions (all $p<0.01$ ). Weekly training load in zone III (volume $\times$ RPE) increased from $477 \pm 650$ to $1,272 \pm 405,(p<0.01)$ between supplementation and HIT phases. Accordingly, weekly training frequency, volume and load in zones I and II were all significantly reduced. Overall training frequency and load did not differ between phases, but total volume was reduced from $491 \pm 238$ during supplementation to $288 \pm 177 \mathrm{~min} /$ weeks during HIT, $(p<0.01)$.

During HIT, subjects always selected the highest tolerable power output, which increased from $266 \pm 33$ to $294 \pm 38 \mathrm{~W}(p<0.01, n=16)$ between the first and last HIT sessions. Overall training PO did not differ between 
groups (pooled mean $84.4 \pm 5.7 \%$ PPO, intergroup $p>0.9)$ and both groups increased training PO similarly from the second to the ninth session (pooled mean $3.9 \pm 2.7 \%$ PPO, intergroup $p=0.70$ ). However, when asked prior to HIT sessions, BAL reported higher subjective state $(8.1 \pm 0.5, n=63)$ and motivation $(9.3 \pm 0.5$, $n=63)$ compared to PLA $(7.3 \pm 0.7$, and $8.4 \pm 0.7$, respectively, $n=81$, both $p=0.01$ ). Moreover, PLA achieved higher peak HR $\left(95.4 \pm 1.2 \% \mathrm{HR}_{\max }, n=9\right)$ and spent overall more time above $90 \% \mathrm{HR}_{\max }(115 \pm 11 \mathrm{~min}$, $n=9)$ during HIT compared to BAL $\left(93.6 \pm 1.0 \% \mathrm{HR}_{\max }\right.$, $93 \pm 17 \mathrm{~min}, n=7$, both between groups $p=0.01$ ). There were no group differences in RPE or blood lactate responses during HIT sessions.

\section{Discussion}

This study investigated the hypothesis that a short HIT block and beta-alanine supplementation would each positively affect physiological determinants of severe exercise, and that combining the two would yield additional benefits. Our main findings were that (1) beta-alanine supplementation increased muscle carnosine, enhanced aerobic energy contribution during severe cycling exercise, and had positive effects on motivation during an intense HIT block; (2) significant increases in muscle carnosine did not affect the muscle homogenate buffering capacity or $\mathrm{pH}$ changes during severe cycling exercise; (3) an 11-day HIT block increased the muscle buffering capacity and glycogen storage, but did not enhance the aerobic energy contribution during severe cycling exercise; and (4) prior supplementation with beta-alanine was associated with greater increases in training intensity, but similar HIT-specific adaptations (improved buffering capacity and glycogen storage), compared to placebo.

One limitation of our study is that we chose a test of fixed intensity and duration rather than an open-ended performance test, while this allowed a better comparison of physiological determinants of severe exercise performance, effects on true performance capacity can only be inferred. Further, in the 90-s FPT, acidosis was less severe than has been observed elsewhere ( $\mathrm{pH} \sim 6.50$, Table 6) (e.g., Messonnier et al. 2007), which was a result of the test being designed to ensure all subjects would finish. Further, the HIT intervention did not induce physiological adaptations in the magnitude we had expected (Breil et al. 2010; Helgerud et al. 2007; Stolen et al. 2005); had there been a substantial increase in $\mathrm{VO}_{2} \max$ following HIT, conclusions about the effects of beta-alanine supplementation on training adaptations could have been made with more certainty. A possible technical limitation was that we adopted relaxation times from literature in the quantification of [carn], which could be influenced by changes in the individual relaxation times; however, these effects are assumed to be minimal and smaller than the observed changes.

As expected, [carn] increased significantly in BAL. While greater increases to [carn] have been reported in studies using higher daily doses or longer supplementation phases (Derave et al. 2007; Harris et al. 2006; Hill et al. 2007; Kendrick et al. 2008), our prescription of $3.2 \mathrm{~g} /$ days for 6 weeks elicited changes similar to those reported after higher dosages elsewhere for $m$. tib. ant. (Baguet et al. 2009) and m. gastroc. (Baguet et al. 2009, 2010a). Ours is the first study to determine [carn] in the quadriceps using non-invasive MRS; assuming $\sim 75 \%$ water weight in skeletal muscle biopsies (personal observation), our values of $7.3 \pm 1.2 \mathrm{mmol} / \mathrm{kg}$ w.w. in $m$. vast. lat. agree well with those reported elsewhere from muscle biopsies (22$28 \mathrm{mmol} / \mathrm{kg}$ d.w.) (Harris et al. 2006; Hill et al. 2007; Kendrick et al. 2008). Moreover, we are the first to report values for $m$. vast. int., which were initially significantly lower than for $m$. vast. lat. $(p<0.01)$, but increased to a greater relative degree $(28.1 \pm 9.6$ vs. $17.9 \pm 5.1 \%)$. This is probably due to a greater proportion of type I fibers in $\mathrm{m}$. vast. int. than for m. vast. lat. (Edgerton et al. 1975; Hill et al. 2007). In accord with Baguet et al. (2009) A similar pattern was seen when comparing lower leg muscles, namely lower initial [carn] but greater relative increases in $m$. tib. ant., which typically has a greater proportion of type I fibers (Johnson et al. 1973), compared to m. gastroc.

We observed an increase in muscle fiber cross-sectional area in type I fibers following beta-alanine supplementation. Although this has not been reported previously, beta-alanine (Hammer and Baltz 2003) and histidine compounds including carnosine (Baslow 1998) are known to act as organic hydrophilic osmolytes. Therefore, we believe the increase in CSA can be attributed to fluid influx due to higher than normal levels of myocellular beta-alanine or carnosine.

Despite increased [carn], beta-alanine did not improve maximal incremental cycling performance, as has been reported elsewhere (Smith et al. 2009; Stout et al. 2007a). Moreover, increased [carn] did not affect the buffering capacity or $\mathrm{pH}$ disturbance during a 90 -s severe cycling bout, which was contrary to our hypothesis. Although Hill et al. supposed that increased buffering capacity must have been behind improved exercise capacity at $110 \%$ PPO after beta-alanine supplementation (2007), measurements of buffering capacity or $\mathrm{pH}$ in muscle biopsies have not been published previously, although one study reported reduced acidosis in blood during a 6-min submaximal exercise bout following beta-alanine supplementation (Baguet et al. 2010b). Our findings suggest that improved capacity for severe exercise after beta-alanine supplementation (Hill et al. 2007; Sale et al. 2011; Smith et al. 2009) could instead be due to other mechanisms. 
Indeed, multiple indicators of severe exercise metabolism were altered in BAL following supplementation. For the same amount of mechanical work, oxygen deficit and muscle lactate accumulation were significantly reduced, while blood lactate accumulation decreased slightly. Realizing that the oxygen deficit may not represent the anaerobic energy turnover per se (Bangsbo 1998), but taking it to be a reliable indicator thereof (Stirling et al. 2008), we take these results to be indicative of enhanced oxidative energy provision and reduced reliance on substrate-level phosphorylation at the same severe intensity in BAL at M2. Previously, addition of carnosine has been shown to enhance muscle activity, in vitro (Boldyrev 2012) and in vivo in animals (Stvolinskii et al. 1992). For example, rats injected with carnosine ran 25-30 \% longer while accumulating less lactate than control animals (Stvolinskii et al. 1992), due perhaps to reduced energy expenditure per unit work or improved mitochondrial coupling (Boldyrev 2012). Observations of such effects (termed "Severin's phenomenon") are not new, but have received relatively little appreciation in recent exercise-related studies of carnosine (an exception being the work of Dutka and Lamb 2004; Dutka et al. 2012) and Everaert et al. (2013). These provide evidence for an enhancing effect of carnosine on $\mathrm{Ca}^{2+}$ release in human type I fibers and $\mathrm{Ca}^{2+}$ sensitivity of the contractile apparatus in both fiber types (Dutka et al. 2012) and improved fatigue resistance (Everaert et al. 2013) in mouse slow-twitch muscle fibers. Although our test was of fixed power and duration, enhanced oxidative energy provision and slower accumulation of glycolytic metabolites which coincide with fatigue are consistent with this phenomenon, and could reveal a mechanism behind improvements in cycling capacity at $110 \%$ PPO reported elsewhere following beta-alanine supplementation (Hill et al. 2007; Sale et al. 2011; Smith et al. 2009).

Finally, we observed intergroup differences in training motivation and training HR during the HIT block. BAL, who performed the training directly following beta-alanine supplementation and with elevated [carn], reported consistently higher subjective states and motivation prior to HIT sessions, which suggests that they felt they could recover better between sessions than PLA. Similarly, Hoffman et al. (2008b) reported reduced feelings of fatigue in football players supplemented with beta-alanine. Animal experiments have reported anti-anxiety effects of beta-alanine supplements (Murakami and Furuse 2010) and antidepressive effects of carnosine (Tomonaga et al. 2008) with the substances affecting the brain directly in both cases. As we made no such measurements, it is unclear whether our findings relate to direct effects on the brain, perception of altered physiology (discussed below), or a combination of both. On the other hand, PLA achieved higher training $\mathrm{HR}$ and spent more time in the target zone $\left(>90 \% \mathrm{HR}_{\max }\right)$ than BAL. While similar observations of increased training load and reduced perceived fatigue have been reported previously (Hoffman et al. 2008a, b), this nonetheless had no influence on the outcome of the HIT block, which were the same for both groups.

We chose not to continue supplementation during the HIT block, based on the slow washout time of carnosine after induced expansion (Baguet et al. 2009). Although carnosine decayed slowly across the second phase as expected, metabolic effects of supplementation observed in BAL at M2 were no longer significant at M3. Thus, it is possible that greater increases in [carn] or extending supplementation until M3 could have affected the outcome of HIT. Alternatively, the shift in energy production back toward greater reliance on anaerobic glycolysis could have been related to small effects on buffering capacity (which we, however, did not measure) following HIT (Parkhouse and McKenzie 1984). Nonetheless, our finding that beta-alanine did not improve training adaptations is consistent with other studies (Hoffman et al. 2008a; Walter et al. 2010). If this is the case, it provides further evidence that carnosine affects high-intensity muscle function primarily by means other than improved acid buffering, since augmenting extramuscular buffers appears to benefit adaptations to HIT (Bishop et al. 2010).

In contrast to our hypothesis, HIT did not increase $V \mathrm{O}_{2} \max$, or $\mathrm{P} \mathrm{VT}_{2}$. Although there was a significant increase in PPO following HIT, this was no larger than that which occurred between M1 and M2. There was also no effect of HIT on aerobic energy contribution during severe cycling, also contrary to our hypothesis. Several previous studies have shown large improvements in $\mathrm{VO}_{2} \max$ after HIT in subjects of similar or greater training status and using intervals similar to those in the present study (Billat et al. 2002; Breil et al. 2010; Demarle et al. 2001; Gross et al. 2007; Vanhatalo et al. 2008; Weston et al. 1997). In particular, Breil et al. (2010), one of the only other published studies to employ such a concentrated phase of HIT, showed that $V \mathrm{O}_{2}$ max was increased by $3 \%$ two days after an 11-day HIT block, but by $6 \%$ following 5 additional days of recovery. This reveals that recovery is a very important factor for the effectiveness of HIT block periodization, and it is possible that our subjects were not fully recovered at the time of M3 testing. On the other hand, our HIT Block comprised fewer sessions than that of Breil et al. (2010) (nine compared to 15), while sessions were of less total volume at a high-intensity compared to other studies using longer, less condensed HIT periods (Demarle et al. 2001; Gross et al. 2007; Weston et al. 1997). Thus, it is possible that our intervention was not sufficient to elicit noticeable changes in $\mathrm{VO}_{2} \max$ in the present group of subjects. Nonetheless, HIT had two important effects, the first being an increase in muscle glycogen storage, the 
other an increase in muscle buffering capacity. Our finding of increased muscle glycogen concentration, in resting and post-exercise biopsies after HIT is consistent with other reports of increased muscle glycogen storage after intense endurance (Perry et al. 2008) or sprint (Gibala and McGee 2008) training or an 11-day HIT block (unpublished data from our lab). This adaptation should translate to improved endurance (Rauch et al. 1995) and repeated-sprint (Rockwell et al. 2003; Skein et al. 2012) performance, and is clearly advantageous for athletes with especially frequent, long, or intense training sessions or competitions. In PLA, there was an increase in PPO between M2 and M2, coincident with increased $\mathrm{BLa}_{\max }$ in the incremental test. This improvement in the power output at volitional exhaustion was evidently not related to improved aerobic condition, as there were no changes in $V \mathrm{O}_{2} \max$ in the incremental or aerobic energy contribution and lactate accumulation at the same absolute power output in the FPT.

The other main effect of HIT was a $7.9 \%$ increase in muscle buffering capacity. This increase had no effect on $\mathrm{pH}$ disturbance during the FPT, but is relatively small compared to the $17 \%$ improvement in buffering capacity after six interval sessions of similar intensity, but greater volume (total 30-40 min of intervals per session) reported by Weston et al. (1997) or a $25 \%$ increase in buffering capacity of elite junior alpine skiers following an 11-day, 15-session HIT block (unpublished data from our lab). The greater effects in those studies could be due to the larger training volume at high-intensity. Despite a small effect size $(d=0.5)$ in the present study, it is noteworthy that this improvement was significant whereas the supplement beta-alanine, in contrast to our hypothesis, had no such effect. Practicians aiming to enhance the buffering capacity should, therefore, first consider short training interventions, as shown here and elsewhere (Edge et al. 2006; Weston et al. 1997), before reaching for oral sport supplements such as beta-alanine.

In conclusion, beta-alanine could be useful for enhancing aerobic energy contribution during severe exercise, or supporting energy balance and psychological stability during intense training phases. In addition, we recommend short blocks of HIT for athletes performing repeated-sprint activities, where glycogen depletion and acidosis limit the performance (Bishop et al. 2004; Girard et al. 2011). In future work, it will be interesting to explore the location and mechanism of changes in severe exercise energy provision and how these perhaps relate to effects of carnosine on muscle contractility.

Acknowledgments This project was supported by research grants from the Swiss Federal Office of Sport (project 10-14) and the Swiss National Science Fund (project 320030_135743).

\section{References}

Abe H (2000) Role of histidine-related compounds as intracellular proton buffering constituents in vertebrate muscle. Biochemistry (Mosc) 65:757-765

Baguet A, Reyngoudt H, Pottier A, Everaert I, Callens S, Achten E, Derave W (2009) Carnosine loading and washout in human skeletal muscles. J Appl Physiol 106:837-842

Baguet A, Bourgois J, Vanhee L, Achten E, Derave W (2010a) Important role of muscle carnosine in rowing performance. J Appl Physiol 109:1096-1101

Baguet A, Koppo K, Pottier A, Derave W (2010b) Beta-alanine supplementation reduces acidosis but not oxygen uptake response during high-intensity cycling exercise. Eur J Appl Physiol 108:495-503

Bangsbo J (1998) Quantification of anaerobic energy production during intense exercise. Med Sci Sports Exerc 30:47-52

Bangsbo J, Gollnick PD, Graham TE, Juel C, Kiens B, Mizuno M, Saltin B (1990) Anaerobic energy production and $\mathrm{O}_{2}$ deficit-debt relationship during exhaustive exercise in humans. J Physiol 422:539-559

Baslow MH (1998) Function of the N-acetyl-L-histidine system in the vertebrate eye. Evidence in support of a role as a molecular water pump. J Mol Neurosci 10:193-208

Begum G, Cunliffe A, Leveritt M (2005) Physiological role of carnosine in contracting muscle. Int $\mathbf{J}$ Sport Nutr Exerc Metab 15:493-514

Bergstrom J (1975) Percutaneous needle biopsy of skeletal muscle in physiological and clinical research. Scand J Clin Lab Invest 35:609-616

Billat VL, Mille-Hamard L, Demarle A, Koralsztein JP (2002) Effect of training in humans on off- and on-transient oxygen uptake kinetics after severe exhausting intensity runs. Eur J Appl Physiol 87:496-505

Billat V, Hamard L, Koralsztein JP, Morton RH (2009) Differential modeling of anaerobic and aerobic metabolism in the 800-m and 1,500-m run. J Appl Physiol 107:478-487

Billeter R, Weber H, Lutz H, Howald H, Eppenberger HM, Jenny E (1980) Myosin types in human skeletal muscle fibers. Histochemistry 65:249-259

Bishop D, Edge J, Goodman C (2004) Muscle buffer capacity and aerobic fitness are associated with repeated-sprint ability in women. Eur J Appl Physiol 92:540-547

Bishop D, Edge J, Thomas C, Mercier J (2008) Effects of highintensity training on muscle lactate transporters and postexercise recovery of muscle lactate and hydrogen ions in women. Am J Physiol Regul Integr Comp Physiol 295:R1991-R1998

Bishop DJ, Thomas C, Moore-Morris T, Tonkonogi M, Sahlin K, Mercier J (2010) Sodium bicarbonate ingestion prior to training improves mitochondrial adaptations in rats. Am J Physiol Endocrinol Metab 299:E225-E233

Boldyrev AA (2000) Problems and perspectives in studying the biological role of carnosine. Biochemistry (Mosc) 65:751-756

Boldyrev AA (2012) Carnosine: new concept for the function of an old molecule. Biochemistry (Mosc) 77:313-326

Breil FA, Weber SN, Koller S, Hoppeler H, Vogt M (2010) Block training periodization in alpine skiing: effects of 11-day HIT on $\mathrm{VO}\left({ }_{2} \mathrm{max}\right)$ and performance. Eur J Appl Physiol 109:1077-1086

Carr AJ, Hopkins WG, Gore CJ (2011) Effects of acute alkalosis and acidosis on performance: a meta-analysis. Sports Med 41:801-814

de Koning JJ, Foster C, Lampen J, Hettinga F, Bobbert MF (2005) Experimental evaluation of the power balance model of speed skating. J Appl Physiol 98:227-233 
Dekerle J, Baron B, Dupont L, Vanvelcenaher J, Pelayo P (2003) Maximal lactate steady state, respiratory compensation threshold and critical power. Eur J Appl Physiol 89:281-288

Demarle AP, Slawinski JJ, Laffite LP, Bocquet VG, Koralsztein JP, Billat VL (2001) Decrease of $\mathrm{O}(2)$ deficit is a potential factor in increased time to exhaustion after specific endurance training. J Appl Physiol 90:947-953

Derave W, Ozdemir MS, Harris RC, Pottier A, Reyngoudt H, Koppo K, Wise JA, Achten E (2007) Beta-Alanine supplementation augments muscle carnosine content and attenuates fatigue during repeated isokinetic contraction bouts in trained sprinters. J Appl Physiol 103:1736-1743

Duffield R, Edge J, Bishop D (2006) Effects of high-intensity interval training on the $\mathrm{VO}_{2}$ response during severe exercise. J Sci Med Sport 9:249-255

Dutka TL, Lamb GD (2004) Effect of carnosine on excitation-contraction coupling in mechanically-skinned rat skeletal muscle. $\mathrm{J}$ Muscle Res Cell Motil 25:203-213

Dutka TL, Lamboley CR, McKenna MJ, Murphy RM, Lamb GD (2012) Effects of carnosine on contractile apparatus $\mathrm{Ca}(2)(+)$ sensitivity and sarcoplasmic reticulum $\mathrm{Ca}(2)(+)$ release in human skeletal muscle fibers. J Appl Physiol 112:728-736

Edge J, Bishop D, Goodman C (2006) The effects of training intensity on muscle buffer capacity in females. Eur J Appl Physiol 96:97-105

Edgerton VR, Smith JL, Simpson DR (1975) Muscle fibre type populations of human leg muscles. Histochem J 7:259-266

Everaert I, Stegen S, Vanheel B, Taes Y, Derave W (2013) Effect of beta-alanine and carnosine supplementation on muscle contractility in mice. Med Sci Sports Exerc 45:43-51

Ferguson RA (2010) Limitations to performance during alpine skiing. Exp Physiol 95:404-410

Foster C, Florhaug JA, Franklin J, Gottschall L, Hrovatin LA, Parker S, Doleshal P, Dodge C (2001) A new approach to monitoring exercise training. J Strength Cond Res 15:109-115

Gibala MJ, McGee SL (2008) Metabolic adaptations to short-term high-intensity interval training: a little pain for a lot of gain? Exerc Sport Sci Rev 36:58-63

Girard O, Mendez-Villanueva A, Bishop D (2011) Repeated-sprint ability: part I: factors contributing to fatigue. Sports Med 41:673-694

Gross M, Swensen T, King D (2007) Nonconsecutive- versus consecutive-day high-intensity interval training in cyclists. Med Sci Sports Exerc 39:1666-1671

Hammer MA, Baltz JM (2003) Beta-alanine but not taurine can function as an organic osmolyte in preimplantation mouse embryos cultured from fertilized eggs. Mol Reprod Dev 66:153-161

Harris RC, Tallon MJ, Dunnett M, Boobis L, Coakley J, Kim HJ, Fallowfield JL, Hill CA, Sale C, Wise JA (2006) The absorption of orally supplied beta-alanine and its effect on muscle carnosine synthesis in human vastus lateralis. Amino Acids 30:279-289

Helgerud J, Hoydal K, Wang E, Karlsen T, Berg P, Bjerkaas M, Simonsen T, Helgesen C, Hjorth N, Bach R, Hoff J (2007) Aerobic high-intensity intervals improve $\mathrm{VO}_{2}$ max more than moderate training. Med Sci Sports Exerc 39:665-671

Hill CA, Harris RC, Kim HJ, Harris BD, Sale C, Boobis LH, Kim CK, Wise JA (2007) Influence of beta-alanine supplementation on skeletal muscle carnosine concentrations and high intensity cycling capacity. Amino Acids 32:225-233

Hoffman J, Ratamess NA, Ross R, Kang J, Magrelli J, Neese K, Faigenbaum AD, Wise JA (2008a) Beta-alanine and the hormonal response to exercise. Int J Sports Med 29:952-958

Hoffman JR, Ratamess NA, Faigenbaum AD, Ross R, Kang J, Stout JR, Wise JA (2008b) Short-duration beta-alanine supplementation increases training volume and reduces subjective feelings of fatigue in college football players. Nutr Res 28:31-35
Hopkins WG, Marshall SW, Batterham AM, Hanin J (2009) Progressive statistics for studies in sports medicine and exercise science. Med Sci Sports Exerc 41:3-13

Jackson AS, Pollock ML (1978) Generalized equations for predicting body density of men. Br J Nutr 40:497-504

Johnson MA, Polgar J, Weightman D, Appleton D (1973) Data on the distribution of fibre types in thirty-six human muscles. An autopsy study. J Neurol Sci 18:111-129

Jones AM, Vanhatalo A, Burnley M, Morton RH, Poole DC (2010) Critical power: implications for determination of $\mathrm{VO}_{2} \max$ and exercise tolerance. Med Sci Sports Exerc 42:1876-1890

Kendrick IP, Harris RC, Kim HJ, Kim CK, Dang VH, Lam TQ, Bui TT, Smith M, Wise JA (2008) The effects of 10 weeks of resistance training combined with beta-alanine supplementation on whole body strength, force production, muscular endurance and body composition. Amino Acids 34:547-554

Laursen PB, Shing CM, Peake JM, Coombes JS, Jenkins DG (2002) Interval training program optimization in highly trained endurance cyclists. Med Sci Sports Exerc 34:1801-1807

Lowry OH, Passonneau JV (1972) A flexible system of enzymatic analysis. Academic Press, New York

Märzendorfer PJ (2011) Reliabilität der EPOC-O2-Defizit Relation und des totaled Energieverbrauchs bei einem 90 sek supramaximalen Leistungstest \& Funktionelle Aspekte und Verträglichkeit einer sechswöchigen Beta-Alanin Supplementierung. Biology. ETH Zürich

Messonnier L, Kristensen M, Juel C, Denis C (2007) Importance of $\mathrm{pH}$ regulation and lactate/ $\mathrm{H}+$ transport capacity for work production during supramaximal exercise in humans. J Appl Physiol 102:1936-1944

Murakami T, Furuse M (2010) The impact of taurine- and betaalanine-supplemented diets on behavioral and neurochemical parameters in mice: antidepressant versus anxiolytic-like effects. Amino Acids 39:427-434

Ozdemir MS, Reyngoudt H, De Deene Y, Sazak HS, Fieremans E, Delputte S, D’Asseler Y, Derave W, Lemahieu I, Achten E (2007) Absolute quantification of carnosine in human calf muscle by proton magnetic resonance spectroscopy. Phys Med Biol 52:6781-6794

Parkhouse WS, McKenzie DC (1984) Possible contribution of skeletal muscle buffers to enhanced anaerobic performance: a brief review. Med Sci Sports Exerc 16:328-338

Perneger TV (1998) What's wrong with Bonferroni adjustments. BMJ 316:1236-1238

Perry CG, Heigenhauser GJ, Bonen A, Spriet LL (2008) High-intensity aerobic interval training increases fat and carbohydrate metabolic capacities in human skeletal muscle. Appl Physiol Nutr Metab 33:1112-1123

Rauch LH, Rodger I, Wilson GR, Belonje JD, Dennis SC, Noakes TD, Hawley JA (1995) The effects of carbohydrate loading on muscle glycogen content and cycling performance. Int J Sport Nutr 5:25-36

Rockwell MS, Rankin JW, Dixon H (2003) Effects of muscle glycogen on performance of repeated sprints and mechanisms of fatigue. Int J Sport Nutr Exerc Metab 13:1-14

Sale C, Saunders B, Hudson S, Wise JA, Harris RC, Sunderland CD (2011) Effect of beta-alanine plus sodium bicarbonate on high-intensity cycling capacity. Med Sci Sports Exerc 43: 1972-1978

Seiler KS, Kjerland GO (2006) Quantifying training intensity distribution in elite endurance athletes: is there evidence for an "optimal" distribution? Scand J Med Sci Sports 16:49-56

Skein M, Duffield R, Kelly BT, Marino FE (2012) The effects of carbohydrate intake and muscle glycogen content on self-paced intermittent-sprint exercise despite no knowledge of carbohydrate manipulation. Eur J Appl Physiol 112:2859-2870 
Smith AE, Walter AA, Graef JL, Kendall KL, Moon JR, Lockwood CM, Fukuda DH, Beck TW, Cramer JT, Stout JR (2009) Effects of beta-alanine supplementation and high-intensity interval training on endurance performance and body composition in men; a double-blind trial. J Int Soc Sports Nutr 6:5

Stellingwerff T, Anwander H, Egger A, Buehler T, Kreis R, Decombaz J, Boesch C (2012) Effect of two beta-alanine dosing protocols on muscle carnosine synthesis and washout. Amino Acids 42:2461-2472

Stepto NK, Hawley JA, Dennis SC, Hopkins WG (1999) Effects of different interval-training programs on cycling time-trial performance. Med Sci Sports Exerc 31:736-741

Stirling JR, Zakynthinaki MS, Billat V (2008) Modeling and analysis of the effect of training on $\mathrm{VO}_{2}$ kinetics and anaerobic capacity. Bull Math Biol 70:1348-1370

Stolen T, Chamari K, Castagna C, Wisloff U (2005) Physiology of soccer: an update. Sports Med 35:501-536

Storen O, Bratland-Sanda S, Haave M, Helgerud J (2012) Improved $\mathrm{VO}_{2}$ max and time trial performance with more high aerobic intensity interval training and reduced training volume: a case study on an elite national cyclist. J Strength Cond Res 26:2705-2711

Stout JR, Cramer JT, Zoeller RF, Torok D, Costa P, Hoffman JR, Harris RC, O'Kroy J (2007a) Effects of beta-alanine supplementation on the onset of neuromuscular fatigue and ventilatory threshold in women. Amino Acids 32:381-386

Stout JR, Sue Graves B, Cramer JT, Goldstein ER, Costa PB, Smith AE, Walter AA (2007b) Effects of creatine supplementation on the onset of neuromuscular fatigue threshold and muscle strength in elderly men and women (64-86 years). J Nutr Health Aging 11:459-464

Stvolinskii SL, Dobrota D, Mezeshova V, Liptai T, Pronaiova N, Zalibera L, Boldyrev AA (1992) Carnosine and anserine in working muscles-study using proton NMR spectroscopy. Biokhimiia 57:1317-1323

Tomonaga S, Yamane H, Onitsuka E, Yamada S, Sato M, Takahata Y, Morimatsu F, Furuse M (2008) Carnosine-induced antidepressant-like activity in rats. Pharmacol Biochem Behav 89:627-632

Van Thienen R, Van Proeyen K, Vanden Eynde B, Puype J, Lefere T, Hespel P (2009) Beta-alanine improves sprint performance in endurance cycling. Med Sci Sports Exerc 41:898-903

Vanhatalo A, Doust JH, Burnley M (2008) A 3-min all-out cycling test is sensitive to a change in critical power. Med Sci Sports Exerc 40:1693-1699

Walter AA, Smith AE, Kendall KL, Stout JR, Cramer JT (2010) Six weeks of high-intensity interval training with and without betaalanine supplementation for improving cardiovascular fitness in women. J Strength Cond Res 24:1199-1207

Weber CL, Schneider DA (2002) Increases in maximal accumulated oxygen deficit after high-intensity interval training are not gender dependent. J Appl Physiol 92:1795-1801

Weibel ER (1979) Stereological methods, vol I: practical methods for biological morphometry. Academic Press, London

Weston AR, Myburgh KH, Lindsay FH, Dennis SC, Noakes TD, Hawley JA (1997) Skeletal muscle buffering capacity and endurance performance after high-intensity interval training by welltrained cyclists. Eur J Appl Physiol Occup Physiol 75:7-13 